\title{
LA CRUZ EN LA GEOMETRÍA DEL COSMOS MAYA
}

\section{María del Carmen Valverde}

\begin{abstract}
One of the most important ideas in the Mesoamerican world was the quadruple division of the space. The mayas were not the exception, and usually this concept was graphicly represented with a cross. So the cross became a cosmological symbol of this culture, having also other meanings wich relate it with the rain, the winds and the tree as axis mundi. This paper tries to show the cross most important meanings, making comparissons between written and iconographic texts.
\end{abstract}

\begin{abstract}
Resumen: Probablemente uno de los conceptos más estables entre los grupos mesoamericanos fue la división cuatripartita del espacio. Los mayas no fueron la excepción, y comúnmente esta idea se representó gráficamente con una cruz. Así, la cruz se convirtió en uno de los símbolos cosmológicos más importantes de esta cultura, revelándose además como portadora de otras valencias que la vinculan con la lluvia, los vientos y el árbol como eje del mundo. Este artículo pretende exponer de manera sintética los significados simbólicos más importantes de la cruz en el cosmos maya, comparando diversas fuentes, desde las escritas hasta las plásticas.
\end{abstract}

De todos los aspectos de la cosmología americana, tal vez ninguno es tan esencial como la división cuatripartita del universo. Esta concepción se refleja tanto en el trazado de los pueblos, el cómputo del tiempo, el ritual, como en algunos jeroglíficos. Gráficamente esta idea se representó con la cruz, que se muestra de diversas formas, e incluso inscrita en círculos en muchas de las manifestaciones artísticas e iconográficas de la antigua América. En cualquiera de sus formas, la cruz es fundamentalmente el símbolo de toda geometría terrestre y celeste, pero sobre todo si está trazada dentro de un círculo, la cruz divide las figuras o los elementos en cuatro porciones iguales, hecho que, entre otras cosas, pudo muy bien haber propiciado su empleo como reguladora de cantidades, Las mar-

Estudios de Cultura Maya. Vol. XXI, 2000

Instituto de Investigaciones Filológicas/

Centro de Estudios Mayas, UNAM

ISSN: 0185-2574 chas del sol, de los astros y la dirección geográfica de los rumbos son elementos que indudablemente han influido, asimismo, en su trazo.

El universo maya, igual que el de otros muchos grupos indigenas americanos, estaba dividido en cuatro partes: cuatro rumbos del mundo, asociados a las cuatro partes del cielo y a las cuatro partes del inframundo; a cada una de éstas correspondió, por lo menos en el Posclásico, un color distinto: al oeste le tocaba el negro; al este, el rojo; al norte, el blanco, y al sur, el amarillo. Existen además cuatro deidades y ciertos objetos y animales relacionados con estos cuatro rumbos:

El pedernal rojo es la sagrada piedra de Ah Chac Mucen Cab. La Madre Ceiba Roja, su Centro Es- 
condido, está en el oriente. El chacalpucté es el árbol de ellos. Suyos son el zapote rojo y los bejucos rojos. Los pavos rojos de cresta amarilla son sus pavos. El maíz rojo y tostado es su maíz.

El pedernal blanco es la sagrada piedra del norte. La Madre Ceiba Blanca es el Centro Invisible de Sac Mucen Cab. Los pavos blancos son sus pavos. Las habas blancas son sus habas. El maíz blanco es su maíz.

El pedernal negro es la piedra del poniente. La Madre Ceiba Negra es su Centro Escondido. El maíz negro y acaracolado es su maíz. El camote de pezón negro es su camote. Los pavos negros son sus pavos. La negra noche es su casa. El frijol negro es su frijol. El haba negra es su haba.

El pedernal amarillo es la piedra del sur. La Madre Ceiba Amarilla es su Centro Escondido. El pucté amarillo es su árbol. Amarillo es su camote. Amarillos son su pavos. El frijol de espalda amarilla es su frijol [Chilam Balam de Chumayel, p. 41].

Este fragmento refleja claramente la idea cuatripartita del cosmos que tenían los mayas de la península de Yucatán. Nos encontramos con los cuatro rumbos del universo asociados a un color, a un árbol, a un pedernal, a un ave, a una deidad, a cierto tipo de maíz y a otros objetos o alimentos sagrados.

En el siglo xv el trazo de todos los pueblos mayas refleja esta organización del cosmos. Nos dice Landa al respecto:

Uso era en todos los pueblos de Yucatán tener hechos dos montones de piedras, uno frente a otro, a la entrada del pueblo y por las cuatro partes del mismo, a saber, oriente, poniente, septentrión y mediodía, para la celebración de las fiestas [Landa, 1982: 63].

Esta visión geométrica del cosmos ya tiene en sí la forma de una cruz con cuatro brazos iguales, pues no hay rumbos mayores o menores, cortos o largos, porque el maya, dondequiera que estuviese, creía encontrarse en el punto céntrico o de origen, de un horizonte circular que limitaba la tierra, y que correspondía a los cuatro rumbos, los cuaInstituto de Investigaciones Filológicas/

Centro de Estudios Mayas, UNAM

ISSN: 0185-2574 tro radios de ese círculo o líneas de iguales dimensiones, que se cortaban perpendicularmente entre sí, formando el signo de la cruz, cuya intersección representa exactamente el citado punto de ubicación u origen (Quiroga, 1977: 141). El centro de esta cruz es el lugar donde se unifican todos los contrarios, en que se resuelven todas las oposiciones. Tenemos entonces aquí expresada la idea de equilibrio, y esta idea se identifica con la armonía del cosmos.

Reafirmando inconcientemente este concepto, los españoles a lo largo de los tres siglos de Colonia, colocan cruces justo en el centro y en las cuatro esquinas de cada pueblo. Francisco Vázquez, en su Crónica de la Provincia de Guatemala, hablando de fray Francisco Colmenar, señala:

Cuidaba en todos los pueblos que fundó, que más de la Santa Cruz que en el templo eremitorio hacia levantar y en el atrio lal centro del pueblo], se pusiese esta divina señal en los cuatro ángulos del pueblo [Vázquez, 1937, II: 193].

El hecho de colocar, por órdenes españolas, cruces en las "cuatro salidas" de cada pueblo, justo donde estaban los montículos de piedra prehispánicos, puede haber dado fuerza al culto de la cruz personificada, teniendo en cuenta que estas pilas de piedra fueron de gran importancia en las ceremonias, particularmente las que tenían conexión con los guardianes de la aldea, que se relacionaban con la dirección, el color y el año que estuviera dominando en ese momento. En este sentido nos dice Torquemada:

Una cosa hubo en estos principios, que movieron a los religiosos a poner cruces por las encrucijadas y entradas de los pueblos: la de ser costumbre entre estos idólatras en su gentilidad, tener idolillos en estos lugares [Torquemada, 1975, 5: 101].

También comenta Donald Thompson que entre los ixiles actualmente las cruces están asocia- 
das con los portadores del año del calendario, $y$ las ceremonias que tienen conexión con estos días son celebradas ante ellas. En concreto, en Nejab, el pueblo ixil más importante, las cruces de los portadores del año están en montículos arqueológicos en las cuatro esquinas del pueblo o cerca de ellos (Thompson, 1964: 24). Estos "cargadores" del año son siempre cuatro, igual que los rumbos del universo o los brazos de la cruz, y son de suma importancia, ya que desde la época prehispánica, los mayas ordenaron y sistematizaron el tiempo. Creían en un conjunto de lapsos que se repetían en forma periódica. Así,

...dentro de grandes ciclos o edades del universo, se produce una infinidad de ciclos menores, cuya imagen es para los mayas la de bultos, que con un mecapal, transportan deidades con forma humana; éstas, que son los números, llegan "cargando el tiempo", recorren un espacio determinado, en alguno de los cuatro rumbos de la tierra, y parten cuando llega su "cansancio", pasando la carga del tiempo a la siguiente deidad / $\mathrm{Cbi}$ lam Balam de Chumayel, p. 20].

En el calendario ritual maya, el tzolkin, sólo hay cuatro días distintos que inicien el ciclo, y éstos son los "portadores del año", los cuales cambiaron según la época. El grupo de portadores más antiguo del que se tiene registro data del Preclásico, y estaba formado por los signos Ik, Manik, Eb y Caban. Durante la época Clásica fueron Akbal, Lamat, Ben y Edznab. Por último, en el horizonte Posclásico nos encontramos con Kan, Muluc, Ix y Cauac, que por ser los portadores más recientes, hacia ellos van dirigidas las ceremonias actuales.

Igual que entre los ixiles, a la fecha, en la mayoría de los pueblos del área maya se continúa con la tradición de poner cruces en las cuatro salidas del pueblo. Entre muchos otros destacan los tzotziles de San Juan Chamula, donde se colocan tres cruces en cada uno de estos puntos. Lo más

Estudios de Cultura Maya. Vol. XXI, 2000

Instituto de Investigaciones Filológicas/

Centro de Estudios Mayas, UNAM

ISSN: 0185-2574 probable es que éstas respondan a la influencia del cristianismo y estén asociadas con el Calvario (Ruz, com. pers., 1994), pero también es posible que esta triple representación del símbolo sea para señalar los tres planos del universo indígena: la región del cielo, la de la tierra y la del mundo de los muertos.

Hay otros pueblos, sobre todo en la península de Yucatán, donde además de la cruz comunal, otras cruces, menos poderosas, son ubicadas también en las cuatro "salidas oficiales" para proporcionar junto con los Balames, protección a la aldea. Incluso, en las oraciones propiciatorias actuales de ciertos ritos, notamos la pervivencia de esta división del cosmos. Thompson rescata una de ellas que fue tomada de Mayapán el siglo pasado por Brasseur de Bourgbourg:

Oh señor [Sol] que estás en lo alto por oriente y en los cuatro rumbos del cielo y en los cuatro rumbos de la tierra: Ahora mi oración va a cada uno de los cuatro extremos de la tierra [J. E. S. Thompson, 1984: 88].

Esta idea cuatripartita del cosmos, y su representación a través de cruces, es común a otros pueblos americanos, tanto contemporáneos como prehispánicos. Por ejemplo, entre los tarascos se habla de los "dioses de las cuatro partes del mundo"; tenemos este mismo tipo de representaciones, entre otros, en los toltecas y los mexicas del altiplano, los muyscas, aymarás, quechuas, araucanos y calchaquíes en Sudamérica, y en la mayor parte de los pueblos indígenas de Norteamérica.

El reconocimiento del símbolo como algo sagrado debió ser un hecho entre estas comunidades desde el momento en que los cuatro brazos de la cruz no son otra cosa que la representación gráfica sencilla y natural de los rumbos. La cruz es la mejor combinación para indicar las direcciones norte, sur, este y oeste, por sus palos, partiendo del punto de intersección de la fi- 
gura. Cada punto cardinal se pone en correspondencia con un rumbo, un color, un dios y una de las estaciones. El solsticio de invierno corresponde al norte, el equinoccio de primavera al este, el solsticio de verano al sur y el equinoccio de otoño al oeste (Génon, 1969: 88).

Así, la cruz está permanentemente relacionada con los ciclos cósmicos. Los brazos corresponden a los diferentes periodos o fases en que se divide el ciclo. Esta división existe a diversas escalas, según se trate de periodos más o menos extensos. Tendríamos, por ejemplo, y para atenernos sólo al orden de la existencia terrestre, los cuatro momentos principales del día, las cuatro fases de la luna, las cuatro estaciones del año, etcétera (Génon, 1969: 53-54).

Esto nos habla de un movimiento de rotación que se cumple en torno de un centro o eje inmutable, de este punto fijo que es el origen. El centro imprime a todas las cosas el movimiento, y el movimiento representa la vida. Esta idea de la cruz podría ser equivalente a la de la svástica hindú, pero aquí la rotación, en lugar de estar representada por el trazado de la circunferencia donde está inscrita la cruz, está sólo indicada por líneas agregadas a las extremidades de los brazos de la cruz, con los cuales forman ángulos rectos; esas líneas son tangentes a la circunferencia y marcan la dirección del movimiento. De alguna manera, la cruz y la svástica, en este sentido, representarían a la rueda del sol.

Es por ello que uno de los números predilectos de la mayor parte de los pueblos antiguos $-\mathrm{y}$ los grupos indígenas americanos no son la excepción- es indudablemente el cuatro, especialmente en los pueblos en los que la heliolatría es la base fundamental de la religión (esto se debe, entre otras cosas, al conocimiento que estas comunidades tienen de los solsticios y los equinoccios.) De igual forma, el culto al número cuatro se originaría también en la veneración a los cuatro puntos cardinales, 2 yo pbedece Instituto de Investigaciones Filológicas/

Centro de Estudios Mayas, UNAM

ISSN: 0185-2574 en cierto modo a las leyes aritméticas del universo. Génon dice al respecto:

Esa cifra [el cuatro], en todas las marcas en que figura, tiene una forma que es exactamente la de una cruz en la cual muchas veces el extremo superior del travesaño vertical y uno de los extremos del travesaño horizontal están unidos por una línea oblicua; ahora bien, es incuestionable que la cruz, sin perjuicio de todas sus demás significaciones, es un símbolo del cuaternario [Génon, 1969: 354].

Según este autor, esta interpretación se confirma por el hecho de que hay algunos casos en que el número cuatro, asociado con otros símbolos, "tiene manifiestamente un lugar que ocupa la cruz en otras figuraciones más habituales" (Genón, 1969: 354).

Jung (1982: 97-98) piensa que el cuatro simboliza las partes, las cualidades y los aspectos de lo Uno, y que por lo tanto es un símbolo antiquísimo, probablemente prehistórico, invariablemente relacionado con la idea de una divinidad creadora del mundo. Así podemos pensar que el cuaternario se representa por medio de la cruz y el punto central de ésta sería el Uno, el lugar donde se conjugan todas las fuerzas, la unidad primordial del universo.

Es cierto que el cuaternario se ha considerado siempre y en todas partes como el número propio de la manifestación universal. Génon opina que el cuaternario así constituido se ve como presupuesto por la manifestación, en el sentido de que la presencia de todos sus términos es necesaria para el desarrollo completo de las posibilidades que ella comparta, y agrega: "por eso en el orden de las cosas manifestadas se encuentra siempre particularmente (podría decirse en cierto modo) la 'signatura del cuaternario" (Genón, 1969: 93).

En América, la presencia del cuaternario también es constante. Quiroga comenta que varios 
grupos de indígenas norteamericanos creen en la existencia de cuatro espíritus correspondientes a los cuatro puntos cardinales. Los creeks divinizaron especialmente al número cuatro, y en la fiesta del Busk prendian fuego en cruz, o sea, en cuatro esquinas. Los dakotas, lo mismo que muchos otros pueblos, tienen en sus origenes étnicos o sociales la tradición de cuatro hermanos, de cuatro semidioses, de cuatro jefes, de cuatro caudillos, etc. Asimismo, los navajos nacieron de cuatro espíritus. En América Central y del Sur, entre los caribes y los muyscas el cuatro se encuentra repetido en muchas de sus tradiciones mitológicas. Los araucanos hacen todas sus invocaciones cuatro veces (Quiroga, 1977: 90-91).

De la misma forma, entre los nahuas, por ejemplo, las plegarias se ofrecen cuatro veces al día; cualquier tipo de ofrenda se hacía a los cuatro puntos del espacio; la jornada de las "almas" era de cuatro días; un fuego ardía y una flecha era tirada a los cuatro puntos cardinales; celebraban cuatro festividades principales al año. Antonio de Solís en su Historia de la Nueva España o la conquista de México nos ofrece una descripción de la gran plaza de la ciudad de México-Tenochtitlan, donde podemos ver la importancia del número cuatro en la distribución arquitectónica de los edificios.

Tenía la plaza cuatro puertas correspondientes a sus cuatro lienzos, que miraban a los cuatro vientos. En lo alto de los portales había cuatro estatuas [...] el ídolo portaba cuatro varas con cabezas de sierpes y cuatro saetas (cit. en Quiroga, 1977: 90-91).

Para los mayas, la representación de la cruz también estuvo íntimamente relacionada con los cuatro vientos. En el Chilam Balam de Chumayel se mencionan los cuatro ángeles, los Espíritus, los Cángeles $I k$, que vendrían a ser los ángeles de los vientos. Esta tradición se conserva hasta la actualidad en muchos pueblos mayas, donde an- tes de quemar la milpa se hace una invocación a los cuatro dioses del viento, hacia los cuatro puntos cardinales en las cuatro esquinas de la parcela, para que protejan la cosecha.

En la ceremonia del Chac-chac, que a la fecha se sigue realizado en la península de Yucatán con el objeto de invocar a los Chaques el favor de la lluvia, aparece una serie de motivos que tiene que ver con la cruz y el número cuatro, como el plano terrestre en forma cuadrangular y las cuatro esquinas del mundo con su deidad correspondiente. Villa Rojas la describe así:

Se construye un altar rústico de troncos, de forma cuadrangular, que representa el plano terrestre. En sus cuatro esquinas se distribuyen cuatro individuos que personifican a los "grandes Chaques" [Villa Rojas, 1968: 132].

Otra celebración de los mayas yucatecos es la de okotbatan. Ésta es la ceremonia más importante del ciclo agrícola, y su función es la de pedir lluvias. Aquí también la presencia de la cruz es fundamental. Primero se bendice el pan en forma de cruz, luego se llevan ofrendas a las cruces que están en la entrada del pueblo, y como parte del ritual se hacen invocaciones a los cuatro dioses de la lluvia, que están en las cuatro esquinas del cielo (Villa Rojas, 1945: 113116).

Entre los mayas de la época prehispánica, la presencia del número cuatro en los mitos cosmogónicos también es constante. En el Popol Vub cuando se narra la creación del hombre por los dioses, son cuatro animales: Yac (el gato de monte), Utiú (el coyote), Quel (una cotorra) y Hoh (el cuervo), los que llevan el maíz blanco y el maíz amarillo - material del que debía ser constituido el ser humano-, a los "Creadores y Formadores". Posteriormente, Tepeu y Gucumatz, los "Progenitores", forman a los cuatro primeros hombres: Balam-Quitzé, Balam-Acab, Mahucutah e Iqui-Balam, con sus respectivas muje- 
res: Cahá-Paluna, Chomihá, Tzununihá y Caquixahá. Dice a continuación este mismo texto:

Ellos engendraron a los hombres, a las tribus pequeñas y a las tribus grandes, y fueron el origen de nosotros, la gente del Quiché. Muchos eran los sacerdotes y sacrificadores; no eran solamente cuatro, pero estos cuatro fueron los progenitores de nosotros la gente del Quiché [Popol Vub, p. 107].

Igual que entre otros grupos indígenas, también entre los mayas encontramos la presencia de estos cuatro primeros hombres que hacen las veces de guías o caudillos del grupo durante las migraciones, y que son el origen de las distintas tribus que después van a fundar las principales ciudades. En el libro del Chilam Balam de Chumayel esta idea se repite cuando se mencionan las cuatro partidas que salieron de cada uno de los rumbos del universo a fundar Chichén Itzá:

Cuatro Abau es el Katün en que sucedió que buscaron Chichén Itzá. Allí fue compuesto lo Maravilloso para ellos por sus Padres. Cuatro partidas salieron. "Las Cuatro divisiones de la tierra" se nombran. Del oriente, a Kincolahpetén fue una Partida. Del norte, a Naco-cob "salió" una Partida. Aquí "salió" una Partida. A Haltún Suyuah "salió" una Partida. Cuatro Montañas son. [...] Cuatro Abau es el Katún en que sucedió que invitaron a los de las Cuatro Divisiones, nombradas Cantzuculcab, para que vinieran. Fueron "hechos padres" cuando vinieron a Chichén Itzá [Chilam Balam de Cbumayel, pp. 146-147].

La importancia del número cuatro en esta cita es evidente. No sólo son cuatro partidas las que salen a Chichén Itzá, sino que también se mencionan "las cuatro divisiones de la tierra", los puntos cardinales, las "Cuatro Montañas", y todo esto sucede en un Katun cuatro Abau.

Entonces, la presencia del cuaternario entre los mayas se constata desde sus orígenes cosInstituto de Investigaciones Filológicas/

Centro de Estudios Mayas, UNAM

ISSN: 0185-2574 mogónicos y permea toda su estructura del mundo. De hecho, dentro de su mitología, después de la tercera destrucción del mundo, en que el cielo cae sobre la tierra, son cuatro bacabes los que lo levantan, y a la fecha, durante esta cuarta creación en que vivimos, lo siguen sosteniendo. Así se representan en los códices (véanse pp. 75-76 del Códice Madrid, donde los cuatro sectores del cosmos se muestran en forma gráfica; figura 1); en los Libros de Chilam Balam se mencionan cuatro árboles, cuatro ceibas sagradas en cada uno de los rumbos, sobre las que se posan cuatro pájaros, también sagrados, y en cada una de estas direcciones del universo se localiza uno de estos Bacabes o Pahuahtunes (literalmente "cargadores del mundo") a manera de columnas del cielo, que sostienen cada una de las cuatro partes del mundo:

El Pauah rojo [Chac Pabuabtun]

El Pauah blanco [Zac Pabuabtun]

El Pauah negro [Ek Pabuabtun]

El Pauah amarillo [Kan Pabuabtun]

[Cbilam Balam de Chumayel, pp. 146-147].

Es obvio, como dijimos antes, que todo esto está representado plásticamente la forma de una cruz. Así, son muy numerosos los testimonios de españoles del siglo xvı acerca de cruces prehispánicas en el área maya. El primero en mencionarlas fue Bernal Díaz del Castillo, cuando estuvo en la expedición de Hernández de Córdoba. Él escribió: "En el otro lado de los ídolos había símbolos como cruces" (cit. en Tozzer, 1966: 207). Posteriormente las mencionan Torquemada y López de Cogolludo, quienes dicen haber visto cruces como representación del dios de la lluvia en antiguos templos y centros ceremoniales. Fray Bartolomé de Las Casas describe una de estas cruces en la isla de Cozumel:

En el reino de Yucatán, cuando los nuestros lo descubrieron, hallaron cruces, y una de cal y can- 


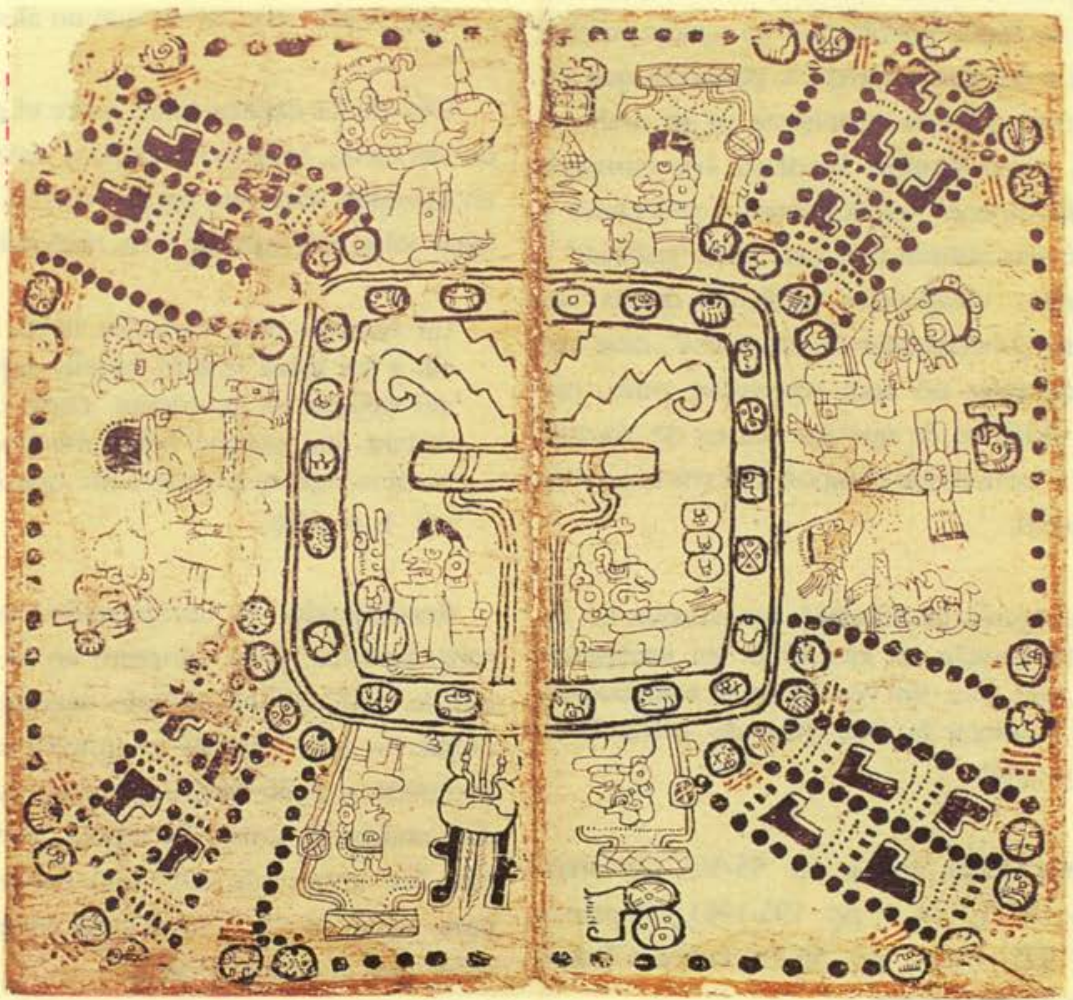

Figura 1. Códice Madrid, pp. 75 y 76

to, de altura de diez palmos, en medio de un patio o cercado muy lucido y almenado, junto a un muy solemne templo, y muy visitado de mucha gente devota, en la isla de Cozumel, que está junto a la tierra firme de Yucatán [Las Casas, 1967, I: 648].

Esta cruz, objeto central en el gran templo de Cozumel, que los misioneros no supieron si admirar o atribuirla a uno de los tantos engaños de Satanás, era de las más veneradas en el área maya en el momento del contacto con los europeos. En tiempo de sequía había peregrinaciones a la isla, y el símbolo era llevado por los naturales en procesión a la orilla de lagos y ríos. De hecho, de acuerdo con el gobernador español que escribe 40 años después de la conquista, Cozumel per- manecía todavía como un centro de peregrinación muy importante para los grupos mayances; tanto -como él mismo lo menciona- "como Jerusalem para los cristianos" (Miller y Farris, 1979: $237-$ 238). De hecho, él mismo cuenta que los frailes católicos no tenían ni la fuerza ni el poder para corregir "estos abusos". Se dice que uno de los frailes fue ahogado por extirpar la idolatría” (Miller y Farris, 1979: 237-238).

Las Casas asentó que, mientras él fue obispo de Chiapas, había una gran veneración por parte de las comunidades indígenas de la región hacia el símbolo de la cruz. Refiere que en el manantial principal o en la vertiente de agua más importante de cada pueblo, los nativos erigían cuatro altares en forma de cruz. 
Evidentemente, a los españoles les intrigó esta adoración de la cruz. Gómara, en su asombro, dice que no había pueblo que no tuviera su cruz de piedra o de otro material. No pensaron que antes de Cristo, en este continente ya se usaba el emblema como símbolo hierático. Los europeos dan al "fenómeno" explicaciones occidentales y muchos frailes utilizan a la cruz para "justificar" a los indígenas. Villagutierre, hablando de las "supersticiones y hechicerías de los indios", dice que algunas de éstas no eran tan malas, pues, por ejemplo, el hecho de que los nativos de Yucatán adoraran la cruz desde tiempos remotos era un indicio positivo:

Menos algunas [hechicerías], que aunque los indios de Yucatán las ejecutaban sin inteligencia de lo que eran, en verdad en sí eran buenas, como el adorar la cruz (Juan de Villagutierre, 1933 , p. 384).

Ximénez (1929, vol. 1, pp. 55-56), Cervantes de Salazar (1971, vol. 1, pp. 195-196) y Román y Zamora (1897, vol. 1, pp. 58-59) también hacen referencia a estas cruces.

De esta forma, cuando los españoles imponen a los mayas la cruz cristiana, sucede lo que dice Gómara (1977: 305): "estos pueblos acataron mucho de alli en adelante la cruz, como quien estaba hecho a tal señal". Sin duda, el ver a los indígenas venerando una cruz presentó a los europeos un serio problema. López de Cogolludo (1971, vol. 1, p. 207) dice al respecto:

Aunque no consta con certidumbre, que en estos reinos de la América haya sido anunciada la predicación evangélica por los mismos apóstoles personalmente, se halló en este reino de Yucatán fundamento para poder presumirlo, y que no dió poco que considerar a los escritores antiguos, pues nuestros españoles, cuando en él entraron, hallaron cruces, y en especial una de piedra $[. .$.$] por donde se pudo entender te-$ ner noticia de nuestra Santa Fe Católica ya perEstudios de Cultura Maya. Vol. XXI, 2000

Instituto de Investigaciones Filológicas/

Centro de Estudios Mayas, UNAM

ISSN: 0185-2574 dida, o por demérito de sus pecados y en castigo de haberse dado a tantas idolatrías como tenían, o por otras causas que no alcanzamos.

Otra de las explicaciones sobre el punto nos la da Las Casas, cuando habla de la cruz encontrada en Cozumel; dice que preguntando a la gente del lugar sobre el origen de ésta, respondían que:

Un hombre muy hermoso había pasado por allí e les había dejado aquella señal para que dél siempre se acordasen. Otros diz que afirmaban que porque había muerto en ella un hombre más resplandeciente que el sol (1967, vol. 1, p. 648).

Resumiendo: el conquistador encontró en toda América, y en concreto en el área maya, que la cruz era un símbolo sagrado, y sin penetrar en los orígenes y motivos de la figura geométrica, y sin tener en cuenta su universalidad como tal, como es lógico, consideró que ésta fue importada del viejo continente, pues para aquél la cruz americana tenía el mismo valor que el signo de su fe.

Por otro lado, hay que tener en cuenta que, además de que la cruz sea el símbolo del "cuatro cifra", es también una figura del "Eje del Mundo". Esto quiere decir que "la cruz tiene también un 'mojón' entre el reino de los cielos y el infierno, pues se erige en medio del cosmos y se extiende hacia todos lados" (Jung, 1982, p. 130).

La cruz es una representación esquemática del árbol como axis mundi, de este punto fijo que funciona como sostén y medio de comunicación del cosmos. Es el punto de apoyo por excelencia; por ello, la comunicación con el cielo o el inframundo sólo puede hacerse alrededor de ella, o incluso por su iniciativa. Porque el árbol cósmico atraviesa todas las regiones celestes y hunde sus raíces en las profundidades subterráneas. La cruz funciona entonces como 
pilar sagrado que equivale al poste cósmico que se encuentra en el centro del universo, y el centro es ante todo, como habíamos mencionado, el origen, el punto de partida de todas las cosas; es el punto principal e indivisible, y por consiguiente "la única imagen que pueda darse de la unidad primordial" (Génon, 1969: 52).

La idea de los cuatro postes con un pilar al centro, de estos cinco puntos donde tenemos las cuatro regiones del espacio, correspondientes a los puntos cardinales, en torno a la región central que vendría a conformar el quinto elemento, es también un arquetipo que se encuentra en la mayor parte de las culturas antiguas, resaltando entre ellas la cultura maya.

Como se señaló, dentro de la cosmología maya, en los puntos cardinales del mundo, se encontraban cuatro árboles, que son ceibas, conocidos como los imix che, término que según Roys puede ser traducido como árbol de la abundancia. Pero había además un quinto árbol sagrado de color verde: yaxcheilcab, o primer árbol del mundo (Roys, 1972: 75) que se localizaba al centro:

Y se levantó el Primer Árbol Blanco (Sac Imix Che, "Ceiba Blanca"), en el Norte. Y se levantó el arco del cielo, señal de la destrucción de abajo. Cuando está alzado el Primer Árbol Blanco, se levantó el Primer Árbol Negro (Ek Imix Che, "Ceiba Negra"), y en él se posó el pájaro de pecho negro. Y se levantó el Primer Árbol Amarillo (Kan Imix Che, "Ceiba amarilla"), y en señal de la destrucción de abajo, se posó el pájaro de pecho amarillo. Y se alzó el Primer Árbol Rojo, Chac Imix Che, "Ceiba Roja" en el [este]. Y se oyeron los pasos de los hombres amarillos, los de semblante amarillo [hombres de maíz].

Y se levantó la Gran Madre Ceiba (Yaax Imix Che, "Ceiba Verde"), en medio del recuerdo de la destrucción de la tierra. Se asentó a la derecha y alzó su copa pidiendo hojas eternas. $\mathrm{Y}$ con sus ramas y sus raíces llamaba a su Señor [Cbilam Balam de Cbumayel, p. 89].
Este árbol verde, evidentemente el más importante, ya que es la "Gran Madre Ceiba", se puede identificar con la ceiba mítica de los mayas modernos, que se alza desde el centro del mundo hasta el cielo. Roys nos dice que es probable que las representaciones estilizadas de estos árboles fueran las cruces que los españoles hallaron por toda el área maya.

La asociación de la cruz a este árbol verde la seguimos encontrando entre los pueblos mayas actuales. Como ejemplo tomemos una plegaria a la Santa Cruz de algunas comunidades de la Península de Yucatán que dice en uno de sus fragmentos:
Señor mío, Padre mío
lo que yo de imploro en la puerta de tu Gloria así como a la Santa Cruz Verde a la Santa Cruz de piedra a la cruz del camino a la cruz del día...

[Arzápalo, 1980: 145].

Asimismo encontramos otras referencias contemporáneas de la cruz como eje del mundo: nos dice $D$. Thompson que un informante de Todos los Santos dijo que la cruz significaba el mundo; que ha existido desde que nació el mundo (1964: 24).

Finalmente podemos decir que el culto a la cruz entre algunas de las comunidades mayas contemporáneas es uno de los ejemplos de cómo este pueblo incorporó dentro de su orden cosmológico al cristianismo, pero en sus propios términos, no como un culto totalmente aceptado, sino con un desarrollo distinto, dando un nuevo giro a lo que ellos ya creían. El hecho de que una serie de tradiciones europeas hayan sido aceptadas con relativa facilidad por los grupos mesoamericanos en general y por los mayas en particular, se debe precisamente a que esta religiosidad prehispánica, en 
la medida en que manejaba arquetipos universales no se contraponía esencialmente al cristianismo. Así, lo que hicieron los mayas fue dar una interpretación mucho más rica que la española o que la suya propia a los distintos símbolos religiosos. Esto fue precisamente lo que sucedió con la cruz.

\section{Bibliografia}

\section{ArZápalo, RAMÓN}

1980 "Contribución para el estudio de la religión maya a través de los textos religiosos modernos", Indiana, núm. 6, Gebr. Man Verlag, Berlín, pp. 137-159.

Casas, Bartolomé de Las

1967 Apologética Historia Sumaria, estudio preliminar Edmundo O'Gorman, 2 vols., Instituto de Investigaciones Históricas, unam, México (Serie Historiadores y Cronistas de Indias, 1).

Cervantes de Salazar, Francisco

1971 Crónica de la Nueva España, estudio preliminar Agustín Millares Carlo, 2 vols., edición Manuel Magallón, Madrid (Biblioteca de Autores Españoles desde la Formación del Lenguaje hasta Nuestros Días, 244-245).

Genón, RenÈ

1969 Símbolos fundamentales de la ciencia sagrada, comp. Michel Valsan, trad. Juan Valmard, Eudeba, Buenos Aires, 419 pp. (Temas de Eudeba, religión).

Jung, Carr. G.

1982 Psicología y religión, prol. Enrique Butelman, Paidós, Barcelona, 441 pp. (Biblioteca de Psicología Profunda, 7).

LANDA, Diego de

1982 Relación de las cosas de Yucatán, introd. Ángel María Garibay, 12a. ed., Porrúa, México, 252 pp. (Biblioteca Porrúa, 13).

Libro de Chilam Balam de Cbumayel

1985 trad. Antonio Mediz Bolio, prol., introd. y notas de Mercedes de la Garza, sEp/Cultura, México, 191 pp. (Cien de México).

López de Cogolludo, Diego 1971 Los tres siglos de la dominación española en

Instituto de Investigaciones Filológicas/

Centro de Estudios Mayas, UNAM

ISSN: 0185-2574
Yucatán o sea, bistoria de esta provincia, 2 vols., Akademische Druck, Graz.

Lópzz de Gomara, Francisco

1977 Conquista de Méjico, Madrid.

Miller G., Arthur, y NANCy M. FArris

1979 "Religios Syncretism in Colonial Yucatán: The Archaelogical and Ethnohistorical Evidence from Tancah, Quintana Roo", en Maya Archaeology and Ethnobistory, University of Texas Press, Austin, pp. 223-240. (Texas Pan American Series).

Popol Vub

1979 Las antiguas bistorias del quicbé, trad. y notas de Adrián Recinos, 12a. ed., Fondo de Cultura Económica, México, 185 pp. (Colección Popular, 11).

QUirogı, Adín

1977 La cruz en América, Castañeda, Buenos Aires, 195 pp. (Estudios Antropológicos, 1).

ROMÁN Y ZAMORA, JERÓNIMO DE

1897 República de Indias. Idolatrías en México y Perí antes de la Conquista, 2 vols., Victoriano Sáez Editor, Madrid (Colección de Libros Raros o Curiosos que Tratan de América, XIV, XV).

ROYS, RALPH L.

1972 The Indian Background of Colonial Yucatán, introd. J. Eric S. Thompson, University of Oklahoma Press, Norman, 244 pp. (The Civilization of the American Indian Series, 118).

Thompson, DONALD E.

1964 The Maya Paganism and Cbristianity. A History of the Fusion of Two Religions, Middle America Research Institute, The Tulane University of Louisiana, Nueva Orleans, $35 \mathrm{pp}$.

Thompson, J. ERic S.

1984 Historia y religión de los mayas, trad. Félix Blanco, 6a. ed., Siglo XXI, México, 485 pp. (América Nuestra, 7).

TORQUEMADA, JUAN DE

1975 Monarquia indiana, introd. sem. de Miguel León Portilla, 3a. ed., 6 vols., Instituto de Investigaciones Históricas, unam, México (Serie Historiadores y Cronistas de Indias, 5).

TOZZER, Alfred M.

1966 Landa's relación de las cosas de Yucatán, 2a. ed., Kraus Reprint Corporation, Nueva York, 394 pp. (Papers of the Peabody Museum 
of American Archaeology and Ethnology, Harvard University, XVIII).

Vízquez, Francisco

1937 Crónica de la Provincia del Santísimo Nombre de Jesús de Guatemala, pról. Lázaro Lamadrid, 2a. ed., 4 vols., Sociedad de Geografia e Historia, Guatemala (Biblioteca "Goathemala", 14-17).

Villagutierre Sotomayor, Junan de

1933 Historia de la conquista de la Provincia de el Itzá, pról. Pedro Zamora Castellanos, 2a. ed., Sociedad de Geografia e Historia, Guatemala, 516 pp. (Biblioteca "Goathemala", 9).

Vima Rojas, Alfonso

1945 The Maya of East Central Quintana Roo,
Carnegie Institution of Washington, Washington, D. C., 182 pp. (Publication, 559).

1968 "Los conceptos de espacio y tiempo entre los grupos mayances contemporáneos", en Miguel León Portilla, Tiempo y realidad en el pensamiento maya. Ensayo de acercamiento, pról. Eric Thompson, Instituto de Investigaciones Históricas, unam, México, 177 pp. (Serie de Culturas Mesoamericanas, 2).

Ximénez, Francisco

1929 Historia de la provincia de San Vicente de Cbiapa y Guatemala de la orden de predicadores, pról. Antonio Villacorta, 3 vols., Guatemala (Biblioteca "Goathemala" de la Sociedad de Geografia e Historia). 